\title{
Research on heating technology of regenerative oxidation used low concentration CBM in small coal mine
}

\author{
WANG Jian-Jun ${ }^{1, a}$ \\ ${ }^{1}$ Chongqing Research Institute Co, Ltd. China
}

\begin{abstract}
Aiming at the problems such as low CBM utilization rate caused by low concentration CBM with methane content less than $8 \%$ extracted from a small coal mine in Hancheng mining area, Shaanxi Province, and serious environmental pollution caused by coal-fired hot blast stove for heating, the heat storage and oxidation heating technology of ultra-low concentration gas in small coal mine was studied by combining field investigation and heat balance calculation, and ultra-low concentration gas regenerative oxidation was obtained through thermal oxidation technology scheme. This technology replaces the coal-fired hot blast stove, realizes "coal and CBM mining and sharing" in the coal mine, and constructs a virtuous cycle development of "promoting drainage by using and promoting safety by drainage". The research shows that: the scheme improves the utilization rate of CBM in the mining area, cancels the consumption of coal combustion, and can use 2.59 million Nm3 of pure CBM every year, generating 1.95 million yuan of economic benefits. And the emissions reduction of $\mathrm{CO} 2$ equivalent is 36000 tons. The benefits of safety, economy and environmental protection are remarkable. This technology is especially suitable for the utilization of ultra-low concentration CBM whose concentration is less than $8 \%$, which has practical significance to improve the CBM utilization rate and promote the realization of the goal of "zero emission".
\end{abstract}

\section{Introduction}

Using low concentration gas thermal storage oxidation technology to replace coal-fired hot blast stove for shaft heating and office building heating can not only effectively solve the problem of air pollutants exceeding the standard of current coal-fired hot blast stove, reduce the emission of air pollutants, avoid the discharge of waste water and solid waste ${ }^{[1-3]}$, with good energy saving and environmental protection benefits, but also make full use of the discharged low concentration gas and save coal. In addition, it can obtain the subsidy for the use of gas, which can bring economic benefits to the $\operatorname{mine}^{[4-5]}$.

\section{General situation of mine}

A coal mine is located in Hancheng mining area, Shaanxi Province, with a production capacity of 1.5 million $\mathrm{T} / \mathrm{A}$. The existing ventilation mode of the mine is mixed type. At present, there are four shafts with air inlet and three shafts with air return ${ }^{[6-8]}$. The air path is long and the negative pressure is large. The industrial site of the mine waste shaft is equipped with waste shaft tower, shaft room, ventilation room, air compressor room, $35 \mathrm{kV}$ substation, boiler room and waste discharge system, which is $4.4 \mathrm{~km}$ away from the adit industrial site. The

ae-mail: wjj251@cqccteg.com waste dump site is close to the southeast of the waste dump shaft industrial site ${ }^{[9]}$. The air intake shaft is located in the east of the industrial site, and the air return shaft is located in the south of the industrial site. A gas drainage pump station is set in the west side of the industrial site of the gangue shaft ${ }^{[10-11]}$.

\section{Utilization scheme of ultra low concentration gas}

For the utilization of coalbed methane, we should not only select the corresponding utilization technology according to local conditions, pay attention to the connection and complementarity of various utilization technologies, but also carry out the optimization research of relevant key technologies, so as to realize the comprehensive effect of cascade utilization of low concentration drainage gas.

It is suggested that the scheme of low concentration gas thermal storage and oxidation thermal energy utilization system should be adopted to replace the original coal-fired hot blast stove. The gas from the shaft 500 pump (I) on the west side of the industrial site of the gangue shaft is sent to the gangue shaft by the low concentration gas safety transmission system, and then through the thermal storage oxidation device, the heat energy is generated to heat the air in the shaft, and to heat the on-site office building. In the process of 
transportation, it is necessary to set up a low concentration gas mixing system to make the gas and air (exhaust) in the pumping station mix evenly, and control the concentration below $1.2 \%$, so as to ensure the safe and stable operation of the device. Figure 1 is the process flow chart of the scheme.

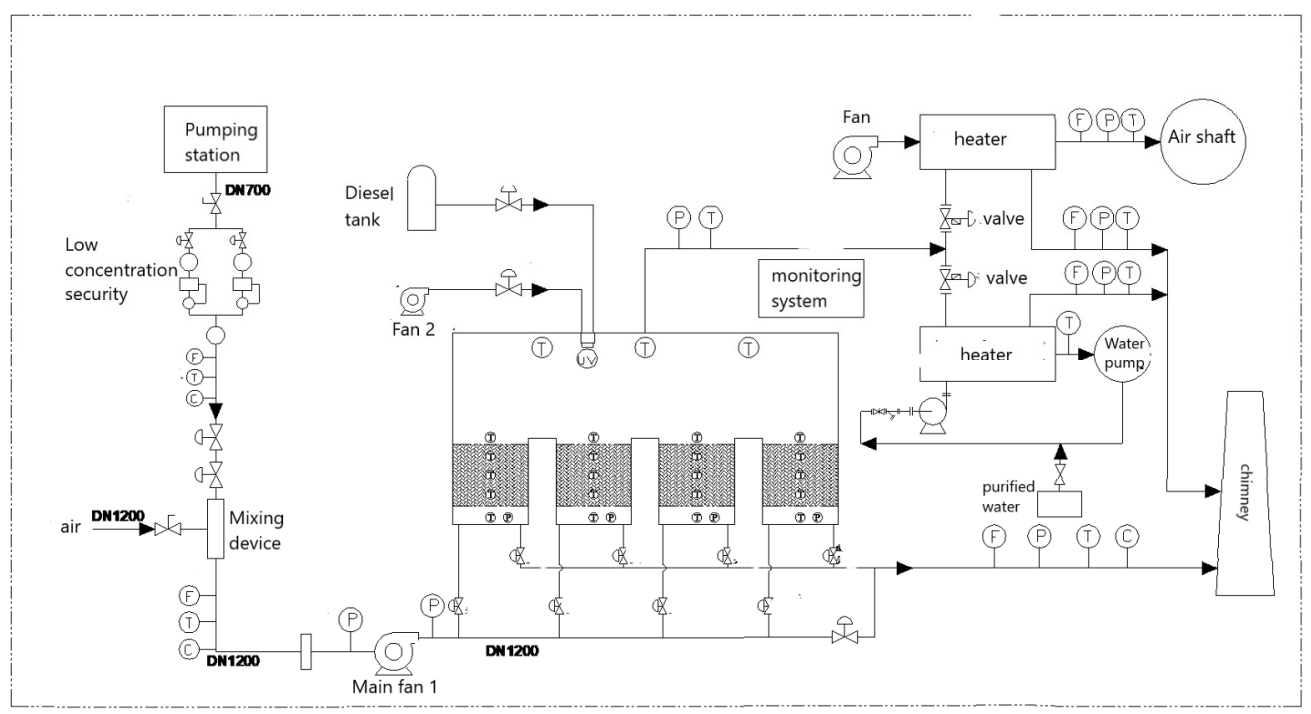

Figure1 Heat storage oxidation heating process

\section{Technical scheme of gas thermal storage oxidation}

\section{1 calculation of mine heat load}

According to the code for design of heating, ventilation and air conditioning in coal industry (GB / T 50466-2008), the heat consumption of anti freezing air into shaft is calculated as follows:

$$
\mathrm{Q}=\mathrm{a} \times \mathrm{G} \times \gamma \times \mathrm{C}_{\mathrm{p}} \times\left(2-\mathrm{t}_{\mathrm{w}}\right)
$$

Where: $\mathrm{Q}$ is the heat consumption of air entering the well, $\mathrm{kW}$; $\mathrm{a}$ is the surplus coefficient, taking $1.1 ; \mathrm{G}$ is the air entering the well, $\mathrm{m} 3$ / $\mathrm{S}$; $\gamma$ is the air bulk density, $\mathrm{kg} / \mathrm{m}^{3} ; \mathrm{C}_{\mathrm{p}}$ is the air specific heat capacity, $\mathrm{kJ} / \mathrm{kg} \cdot{ }^{\circ} \mathrm{C}$; $\mathrm{t}_{\mathrm{w}}$ is the outdoor calculated temperature before air heating, ${ }^{\circ} \mathrm{C}$. The intake air volume of the mine intake shaft is $10000 \mathrm{~nm}^{3} / \mathrm{min}$. That is, $\mathrm{G}=10000 \div 60 \mathrm{~m}^{3} / \mathrm{s}$. After checking the table to determine the physical parameters of air, $Q=1.1 \times 10000 \div 60 \times 1.284 \times 1.01 \times[2-(-14.8)]=3994$ $\mathrm{kW}$

In order to meet the heating demand of the office building in the gangue shaft industrial site, a part of the high-temperature flue gas is separated to the hot water heater for heating water, and then the hot water is led to the office building for heating. The heating area is $1000 \mathrm{~m}^{2}$, the heating index is $140 \mathrm{w} / \mathrm{m}^{2}$, and the building heating load is $140 \mathrm{~kW}$.

The total heat load is $3994+140=4134 \mathrm{~kW}$ 。

\subsection{System scale}

In the thermal energy utilization system of ultra-low concentration gas thermal storage and oxidation, methane is oxidized in the thermal storage and oxidation device and releases heat. Part of the high temperature flue gas is transported to the fresh air heater and hot water heater to generate hot air and hot water. In the process of heat transfer, the thermal efficiency of thermal storage oxidation device is $80 \%$, the thermal efficiency of fresh air heater and hot water heater is $83 \%$, and the heat loss of pipeline is $3 \%$.

The heating load of the coal mine shaft is $3994 \mathrm{kw}$, which is to meet the heating demand. The heating load of the coal mine building is $140 \mathrm{~kW}$, which is to meet the heating demand.

Considering comprehensively, the total amount of oxidized gas required is $10.91+0.382=11.292 \mathrm{~m}^{3} / \mathrm{min}$. Therefore, the scale of thermal storage oxidation unit is selected as $60000 \mathrm{Nm}^{3} / \mathrm{h}$, which can meet the heating demand.

\subsection{Analysis of gas source guarantee}

The mine is located in the north. In the heating season, the underground temperature is lower than $2^{\circ} \mathrm{C}$, and the extreme cold month temperature is $-14.8^{\circ} \mathrm{C}$. In order to smooth coal mining and prevent freezing of working face, it is necessary to ensure that the underground working temperature is not less than $2^{\circ} \mathrm{C}$. Therefore, if the thermal storage oxidation device is used for heating, in order to prevent coal mining stagnation, the heating gas source must be guaranteed.

The gas drainage capacity of the mine is $130 \mathrm{~m}^{3} / \mathrm{min}$, of which the goaf drainage capacity is $50 \mathrm{~m}^{3} / \mathrm{min}$, and the coal pre drainage and pressure relief drainage capacity is $80 \mathrm{~m}^{3} / \mathrm{min}$. Table 1 shows the gas drainage situation of the pumping station on the west side of the gangue drainage shaft square. Shaft 500 pump and shaft 500 pump can provide pure gas of $12.73 \mathrm{Nm}^{3} / \mathrm{min}$ and 2.80 $\mathrm{Nm}^{3} /$ min respectively. At present, this part of gas is vented at high points. In this scheme, only $11.292 \mathrm{Nm}^{3}$ / min pure gas is needed to meet the heating demand of the 
industrial site of waste shaft. In addition, the return air shaft is located in the south of the industrial site of the gangue shaft, the return air volume is $11800 \mathrm{~m}^{3} / \mathrm{min}$, and the gas concentration is $0.2 \%$. Therefore, the gas source is guaranteed.

\subsection{Security measures}

(1) According to the requirements of design specification for safety guarantee system of low concentration gas pipeline transportation in coal mine, multiple safety guarantee measures are set, such as automatic powder spraying and explosion suppression device, water seal fire and explosion suppression device, automatic explosion suppression device, etc.

(2) A power-off protection system is set up, and UPS power supply is adopted to ensure the normal operation of the monitoring system for 30 minutes under the power-off condition, so as to provide power for quick reaction, shut off the gas supply and open the bypass valve. The pneumatic quick shut-off valve installed on the gas extraction pipeline automatically closes when the power is off, so as to prevent the gas extraction from entering the subsequent pipeline and ensure the safety.

(3) When the inlet concentration of the system exceeds the limit, the high-precision methane concentration sensor set on the main pipe can measure quickly and accurately, send control signals, close the inlet valve of the thermal storage oxidation device, the quick closing valve of the gas extraction pipeline, and open the bypass valve of the thermal storage oxidation device to ensure the safety of the system.

The key parts of the valve, such as actuator, burner, high precision and fast response laser concentration sensor and monitoring system, are imported. The thermal storage oxidation device and fresh air heater are mainly structural parts with low failure rate. The overhaul period of the device is more than half a year. During the heating period in winter, there will be no failure shutdown, and the continuous heating is guaranteed. For the switching valve actuator, temperature sensor, concentration sensor and other equipment that may have problems, online maintenance mode can be adopted, which does not affect the normal operation of the system.

In the design of this system, the basic design data such as air intake volume and outdoor calculated temperature provided by the mine are strictly followed, and $10 \%$ design allowance is reserved according to the requirements of relevant specifications, which can fully meet the heating load requirements of the system.

\section{Security measures}

(1) According to the requirements of the code for design of safety guarantee system for low concentration gas pipeline transportation in coal mines (aq1076-2009), multiple safety guarantee measures such as automatic powder injection and explosion suppression device, water seal fire and explosion suppression device and automatic explosion suppression device are set.

(2) A power-off protection system is set up, and UPS power supply is adopted to ensure the normal operation of the monitoring system for 30 minutes under the power-off condition, so as to provide power for quick reaction, shut off the gas supply and open the bypass valve. The pneumatic quick shut-off valve installed on the gas extraction pipeline automatically closes when the power is off, so as to prevent the gas extraction from entering the subsequent pipeline and ensure the safety.

(3) When the inlet concentration of the system exceeds the limit, the high-precision methane concentration sensor set on the main pipe can measure quickly and accurately, send control signals, close the inlet valve of the thermal storage oxidation device, the quick closing valve of the gas extraction pipeline, and open the bypass valve of the thermal storage oxidation device to ensure the safety of the system.

\section{Analysis of practice effect}

The technology of replacing the coal-fired hot blast stove with low concentration gas storage and oxidation technology for wellbore heating and office building heating can not only make full use of the low concentration gas discharged, but also solve the problem of air pollutants, sewage and solid waste discharge. In addition, the comparison between the coal-fired hot air stove and the low concentration gas thermal storage oxidation system shows that the thermal energy utilization system does not consume coal, which can save the cost of coal combustion, and also obtain subsidies for the utilization of gas extraction and production, reducing the operation cost of dedusting and desulfurization. The pure watts of 2.59 million Nm3 can be used every year, which can generate economic benefits of RMB 1.95 million, and the $\mathrm{CO}_{2}$ equivalent of $36000 \mathrm{t}$ is reduced, and the environmental protection benefits are significant.

In terms of heating, even in the extreme cold weather, the temperature of the working face in the coal mine can be guaranteed to be no less than $2^{\circ} \mathrm{C}$, so that the coal mining work normally; Ensure that the temperature in the building of industrial site is not less than $16^{\circ} \mathrm{C}$, and ensure the comfort of working environment.

\section{Conclusion}

(1) The low concentration gas extracted from coal mine is used for thermal storage and oxidation to generate heat energy, which can replace coal-fired hot blast stove for shaft heating and heating for office building. It is in line with the relevant policies of air pollution prevention and CBM utilization in China, and has good energy-saving and environmental protection benefits. At the same time, it can also bring economic benefits for coal mining enterprises.

(2) The construction of ultra-low concentration gas thermal storage oxidation device plays a good demonstration role in optimizing energy structure, improving energy efficiency, realizing low-carbon cycle and promoting energy conservation and emission reduction. This technology is especially suitable for the utilization of ultra-low concentration gas whose 
concentration is less than $8 \%$, which has practical significance to improve the utilization rate of gas and promote the realization of the goal of "zero emission".

(3) The utilization of ultra-low concentration gas realizes the "coal and gas $\mathrm{CO}$ mining and sharing" of coal mine, and constructs a virtuous cycle development of "use to promote drainage, and drainage to promote safety", with significant safety, economic and environmental benefits.

\section{References}

1. Jiang shaorui, Xue Zhigang, Li Wei, et al. Air quality and the impact of air pollution on health in China [J]. North China electric power technology, 2015, 000 (008): 7-13

2. Zhou Hongchun. Air pollution control action plan [J]. Green China, 2017, No. 474 (08): 55-57

3. Kang Jiandong. Experimental study on wellbore heating technology of low concentration gas thermal storage oxidation $[\mathrm{J}]$. Coal science and technology, 2018, 046 (006): 211-216

4. Lian Changjun. Research and practice effect of coal and gas $\mathrm{CO}$ mining and sharing technology in small high gas coal mines $[\mathrm{J}]$. Mining research and development, 2019 (11)

5. Yuan Liang, Xue Junhua. Key technology of non pillar coal and gas CO mining in low permeability coal seam group [J]. Coal science and technology, 2013, 41 (1): 5-11

6. Zhang Xuemin, Zhang Xiaobo, Zhang Zhongxin, et al. Study on gas emission law and its comprehensive control in Yangquan mining area $[\mathrm{J}]$. Coal science and technology, 2014, 42 (9): 123-125

7. Chen Jinhua. Application Research of low concentration gas thermal storage and oxidation heating system $[\mathrm{J}]$. Mining safety and environmental protection, 2017 (2)

8. GB / T 50466-2018, design standard for heating ventilation and air conditioning in coal industry

9. Xiong Yunwei. Research progress of low concentration coalbed methane cascade utilization technology in coal mining area [J]. Mining safety and environmental protection, 2018 (4): 121-124

10. Yang Zhongqing, Zhang Li, Tang Qiang. Research progress on energy utilization technology of ultra-low concentration coalbed methane [J]. Natural gas industry, 2010,30 (2): 115-118

11. Wang Pengfei. Theoretical and experimental study on thermal countercurrent oxidation of low concentration coal mine ventilation gas [D]. Hunan: Central South University, 2012. 